\title{
The Efficacy of Platelet Rich Plasma Combined with Steroid Injection in the Treatment of Resistant Lateral Epicondylitis
}

\section{Dirençli Lateral Epikondilit Tedavisinde Trombositten Zengin Plazma ile Kombine Steroid Enjeksiyonunun Etkinliği}

\author{
Erdem Aktaş ${ }^{1}$, Barış Yılmaz $^{2}$, Baybars Ataoğlu ${ }^{3}$, Murat Arıkan ${ }^{1}$, Güray Toğral ${ }^{1}$, Murat İlikmen ${ }^{4}$ \\ ${ }^{1}$ Dr. A. Y. Ankara Onkoloji Eğitim Ve Araştırma Hastanesi, Ortopedi Ve Travmatoloji Kliniği, Ankara \\ ${ }^{2}$ Fatih Sultan Mehmet Eğitim Ve Araştırma Hastanesi, Ortopedi Ve Travmatoloji Kliniği, İstanbul \\ ${ }^{3}$ Gazi Üniversitesi Tıp Fakültesi Hastanesi, Ortopedi Ve Travmatoloji Ana Bilim Dalı, Ankara \\ ${ }^{4}$ Başkent Üniversitesi Tıp Fakültesi Alanya Hastanesi, Ortopedi Ve Travmatoloji Ana Bilim Dalı, Antalya
}

\section{ÖZET}

Amaç: Lateral epikondilit tedavisinde, otolog trombositten zengin plazma (TZP) ile kombine steroid enjeksiyonu yapılan hastalarda el kavrama gücü, ağrı ve hasta memnuniyeti sonuçlarının değerlendirilmesi. Yöntemler: Unilateral dirençli lateral epikondilit tanısı alan, ortalama yaşı 42.6 olan (23-62 yaş), 26 erkek ve 58 kadın toplam 84 hastaya uygulanan 2 farklı tedavi yöntemi retrospektif olarak incelendi. Ekstensor karpi radialis brevis origosuna 1 hafta ara ile lokal steroid $(0.5 \mathrm{ml}$ Bethametasone $+0.25 \mathrm{ml}$ Prilokain) ve TZP uygulanan hastalar grup 1'e dahil edilirken, grup 2'ye aynı lokalizasyona sadece TZP enjeksiyonu uygulanan hastalar dahil edildi. Hastaların tedavi öncesi ve sonrası 15-30 ve 60. günde kaydedilen el kavrama güçleri ve Verhaar fonksiyonel skorları değerlendirildi.

Bulgular: Grup 1'deki hastaların kavrama gücü tedavi öncesi ortalama $0.42 \pm 0.17$ (0.18-0.63) bar iken, tedavi sonras1 60. günde ortalama $0.68 \pm 0.11(0.38-0.84)$, grup 2'de kavrama gücü tedavi öncesi ortalama $0.45 \pm 0.15$ (0.19-0.67) iken tedavi sonrası 0.66 \pm 0.10 (0.44-082) bar ölçüldü. Grup 1 el kavrama gücünde artış yüzdesi 15 ve 30. günlerde grup 2'ye oranla anlamlı olarak yüksek bulunurken 60. günde 2 grup arasında anlamlı fark bulunmad1 ( $\mathrm{p}=0.277$ ). Verhaar skoru, grup 1'de grup 2'ye oranla 15 ve 30. günlerde anlamlı olarak yüksek iken 60. günde fark bulunamad1.

Sonuç: Tek başına TZP uygulamasına göre, steroid enjeksiyonunu takiben yapılan TZP, azalan el kavrama gücünün erken dönemde geri kazanılması gerekli olan olgularda güvenli ve etkili bir yöntem olarak tercih edilebilir.

Anahtar Kelimeler: Trombositten zengin plazma; Lateral epikondilit; El kavrama gücü

\begin{abstract}
Objective: The evaluation of autologous platelet rich plasma (PRP) and steroid injection on handgrip strenght, pain and patient satisfaction in the treatment of lateral epicondylitis.

Methods: Eighty-four patients, mean age 42.6 (23-62) years, diagnosed with unilateral resistant lateral epicondylitis was evaluated retrospectively. Group1 consisted of patients treated with local steroid injection $(0.5 \mathrm{ml}$ Bethametasone $+0.25 \mathrm{ml}$ Prilokain) and PRP within 1 week interval to extensor carpi radialis brevis origo while group 2 consisted of patients who were subjected to single dose local PRP injection to the same localization. Pre- and post-treatment 15-30-60 day hand grip strength and Verhaar functional score data were evaluated.

Results: Mean pre-treatment grip strenght of group 1 patients were $0.42 \pm 0.17(0.18-0.61)$ bar whereas posttreatment day 60 increased to $0.68 \pm 0.11(0.50-0.85)$. Group 2 mean pre-treatment grip strenght was found to be $0.45 \pm 0.15(0.19-0.84)$ bar, whereas post-treatment day 60 increased to $0.66 \pm 0.10(0.44-082)$. Compared to group 2 , the percentage of grip strength increase in group 1 was significantly higher at days 15 and 30 , whereas there was no difference at day 60 between groups $(\mathrm{p}=0.277)$. Compared to group 2, Verhaar scores were found to be higher in group1 at days 15 and 30, whereas there was no difference between groups at day 60 . Conclusion: Compared to PRP alone, steroid injection 1 week prior PRP administration can be preferred as an effective and safe method in cases which early maintenance of decreased grip strength is mandatory.
\end{abstract}

Key words: Platelet rich plasma; Lateral epicondylitis; Hand grip strength 


\section{Giriş}

Erişkinde en sık tanı konulan dirsek yan ağris1 nedeni lateral epikondilittir (1). Genellikle 3050 yaş arasında ve sıklıkla dominant olarak kullanılan tarafta görülür. Kesin nedeni bilinmemekle birlikte, el bilek ve parmak ekstensörlerinin dirsek lateral epikondili üzerine neden olduğu aşırı mekanik yüklenmenin bu patolojiye sebep olduğu düşünülmektedir (2). Hastalık ilk kez 1973'te Runge tarafindan tanımlanmış ancak 1882'de Morris tarafindan kullanılan tenisçi dirseği ismiyle literatüre girmiştir (3). Klinik, humerusun lateral epikondilinde oluşan ve proksimalden distale, ön kola doğru yayılan ve ekstensör kas grubunu zorlayıcı hareketler ile artan vasıfta ağrı ile karakterizedir. Lateral epikondil üzerine basmakla ve dirsek ekstensiyonda iken el bileğine dirençli dorsifleksiyon, supinasyon yaptırmakla ağr1 hissedilmesi ve el kavrama kuvvetinde azalma tespit edilmesi tipik muayene bulgularıdır. Histopatolojik olarak, el bileği ve parmak ektansörlerinin lateral epikondile yapışma yerinde tendoperiostit, ödem, damarlanmada artış ve granülasyon dokusu gözlenir (4).

Literatürde, tedavi modaliteleri daha çok ağr1 ve hasta memnuniyeti üzerinde yoğunlaşmışken lateral epikondilit için önerilen güncel tedavi metodlarının azalan el kavrama gücünü kısa zamanda geri kazanılması açısından etkinlikleri tartışmalıdır. Alçı-atel ile istirahat, fizik tedavi, ortez kullanımı, botulinum toksini, non-steroid antiinflamatuar ilaçlar, kortikosteroid enjeksiyonu, tam kan enjeksiyonu, ECSW (extracorporal shock wave) ve debridman bahsi geçen güncel tedavi seçenekleridir $(5,6)$. Konsantre edilmiş trombositlerden salgılanan büyüme faktörlerinin (TDGF, TGF- $\beta$, VEGF) etkisini kullanan otolog TZP ise son yillarda pek çok tendinopatide ortopedik cerrahlar tarafindan tercih edilmeye başlanmıştır. Labelle ve ark. yaptığı bir çalışmada lateral epikondilitin doğal seyrinde tedavi edilmeksizin 6 ay içerisinde semptomların gerileyebildiği bildirilmişken, literatürde, uygulanan konservatif ve cerrahi tedavi seçeneklerine rağmen \%10-40 gibi yüksek oranda kronikleşme oranları da mevcuttur (7). Özellikle seçilmiş meslek gruplarında (hekimler, sporcular, çiftçiler, işçiler) kronikleşmeden kaçınmak ve el kavrama gücünün ve yetilerinin hılı ve etkin olarak geri kazanılması tedavinin birinci önceliğini teşkil etmektedir. Dirençli lateral epikondilit olgularında tek başına TZP uygulaması ile ağrı ve fonksiyonel skorlarda başarılı sonuçlar bildirilmesine rağmen hastalık seyri ile azalan el kavrama fonksiyonlarının hizlı geri kazanılması ve kronikleşmenin engellenmesi amaciyla etkin ve standart bir tedavi protokolü halen tariflenmemiştir. Dirençli epikondilit olgularında, steroidin akut antienflamatuar etkisi ve TZP'nin geç ortaya çıkan büyüme faktörü bağımlı rejeneratif etkisinin kombine kullanımının tek başlarına kullanıma göre avantajlı olduğunu düşünmekteyiz. Amaç, özellikle el kavrama gücünün ön planda olduğu meslek grubunda s1k görülen (\%3-9) lateral epikondilitin güncel ve basit bir tedavi şekli olan steroid enjeksiyonu ve son yıllarda popülerlik kazanan otolog TZP kombine kullanımının kısa dönemde el kavrama gücü, ağr1 ve hasta memnuniyeti üzerinde etkinliğini araştırmaktır.

\section{Gereç ve Yöntem}

2013-2014 yılları arasında lateral epikondilit tanısı almış, 3 aylık konservatif tedaviye (nonsteroid antiinflamatuar (NSAI)+ epikondilit band1) rağmen şikayetleri geçmeyen, provokatif testlerde ağrisı olan, ortalama yaş $42.6 \pm 7.3$ (23-62), 84 hastanın (26 E, $58 \mathrm{~K}$ ) dirseği çalışmaya dahil edilerek 2 farklı tedavi yönteminin etkinliği retrospektif olarak değerlendirildi. Dirsek çevresinde kırık ve ameliyat hikayesi olan, başka bir sistemik hastalık nedeniyle NSAİ/ kortikosteroid ilaç tedavisi alan, fizik muayenede dirsek instabilitesi ve hareket açıklık kaybı olan hastalar, başvuru anında önceden kronik lateral epikondilit tanısı nedeni ile cerrahi tedavi almış hasta popülasyonu çalışma kapsamı dışında bırakıldı.

Hastalar uygulanan 2 farklı konservatif tedavi yöntemine göre 2 gruba ayrilarak değerlendirildi. Kırkiki hasta ekstensör karpi radialis brevis origosuna tek doz lokal steroid enjeksiyonu ( $0.5 \mathrm{ml}$ Bethametasone $+0.25 \mathrm{ml}$ Prilokain), 1 hafta sonra otolog TZP (GPS ${ }^{\circledR}$ III) enjekte edilen hastalar grup 1'i oluştururken, 2. gruba ise sadece otolog TZP $\left(\right.$ GPS $^{\circledR}$ III) tedavisi uygulanan 42 hasta dahil edildi.

Hastaların tedavi öncesi ve tedavinin 15-30 ve 60. gününde Jamar el dinamometresi 
(bar) ile ölçülmüş olan el kavrama güçleri ve tedavinin $15-30$ ve 60 . günlerinde Verhaar ve ark.' larının skorlama sistemi kullanılarak kaydedilen fonksiyonel veriler değerlendirildi (8). Verhaar skorlaması lateral epikondilit tedavi başarısını değerlendirmek için kullanılan güncel ve pratik bir klinik değerlendirme sistemi olup, dirençli olgularda tedavi etkinliğinin değerlendirilmesinde rutin olarak kulanılmaktadır (Tablo 1).

Verilerin istatistik analizleri için SPSS 16.0 (SPSS-inc.Chicago A.B.D) program1 kullanıld, $\quad \mathrm{p} \leq 0.05$ istatistiksel anlamlı11k ölçütü olarak alındı. Gruplar arasında ele kavrama ve Verhaar skorları arasındaki fark unpaired Student's t-test kullanılarak analiz edildi.

\section{Sonuçlar}

Lateral epikondilit, hastaların \%78'inde dominant ekstremitede teşhis edilirken, her 2 grupta şikayetlerin süresi ve el kavrama gücü arasinda korelasyon bulunmad $1(\mathrm{p}=0.445, \mathrm{r}=-$ 0.085). Grup 1'deki hastaların kavrama gücü tedavi öncesi ortalama $0.427 \pm 0.17 \quad(0.18$ 0.63 ) bar iken tedavi sonrası 60. gün ortalama
$0.68 \pm 0.11 \quad(0.38-084)$ bar olarak bulundu $(\mathrm{p}=0.001) \quad$ (Tablo1). Grup 2'deki hastaların kavrama gücü tedavi öncesi ortalama $0.45 \pm 0.15(0.19-0.67)$ bar iken, tedavi sonras1 60. gün ortalama $0.66 \pm 0.10 \quad(0.42-0.82)$ bar olarak bulundu ( $\mathrm{p}=0.001)$ (Tablo 2). Her iki tedavi yöntemi el kavrama gücü açısından anlamlı olarak etkin bulunmakla beraber steroid+ TZP uygulanan grupta sadece TZP'ye oranla 15. gün ortalama el kavrama gücü artmış olarak bulundu. Altmışıncı gün sonunda grup 1 ortalama el kavrama gücü artış yüzdesi $0.51 \pm 0.33$ (0.1-1.4), grup 2 ortalama el kavrama gücü artış yüzdesi $0.44 \pm 0.31$ (0.11.8) olarak bulundu ( $\mathrm{p}=0.277$ ). (Tablo 2, Şekil $1)$.

Grup 1'de tedavi sonrası ağr1 ve hasta memnuniyeti açısından Verhaar skorlama sistemine göre $\% 72.72$ mükemmel, $\% 21.21$ iyi ve $\% 6.07$ orta sonuç elde edilirken grup 2'de $\% 64.70$ mükemmel, $\% 23.52$ iyi, $\% 5.89$ orta ve \%5.89 kötü sonuç elde edildi. Verhaar skoru grup 1 ve 2 arasında 15 ve 30 . günlerde TZP + steroid enjeksiyonu uygulanan grupta anlamlı olarak yüksek bulunmuşken iken 60 . günde iki grup arasinda fark saptanmadi (sirasiyla $p=$ $0.002, p=0.028, p=0.720)$ (Tablo 3, Şekil 2).

Tablo1: Lateral epikondilit için Verhaar ve ark.' larının klinik değerlendirme skorlama sistemi.

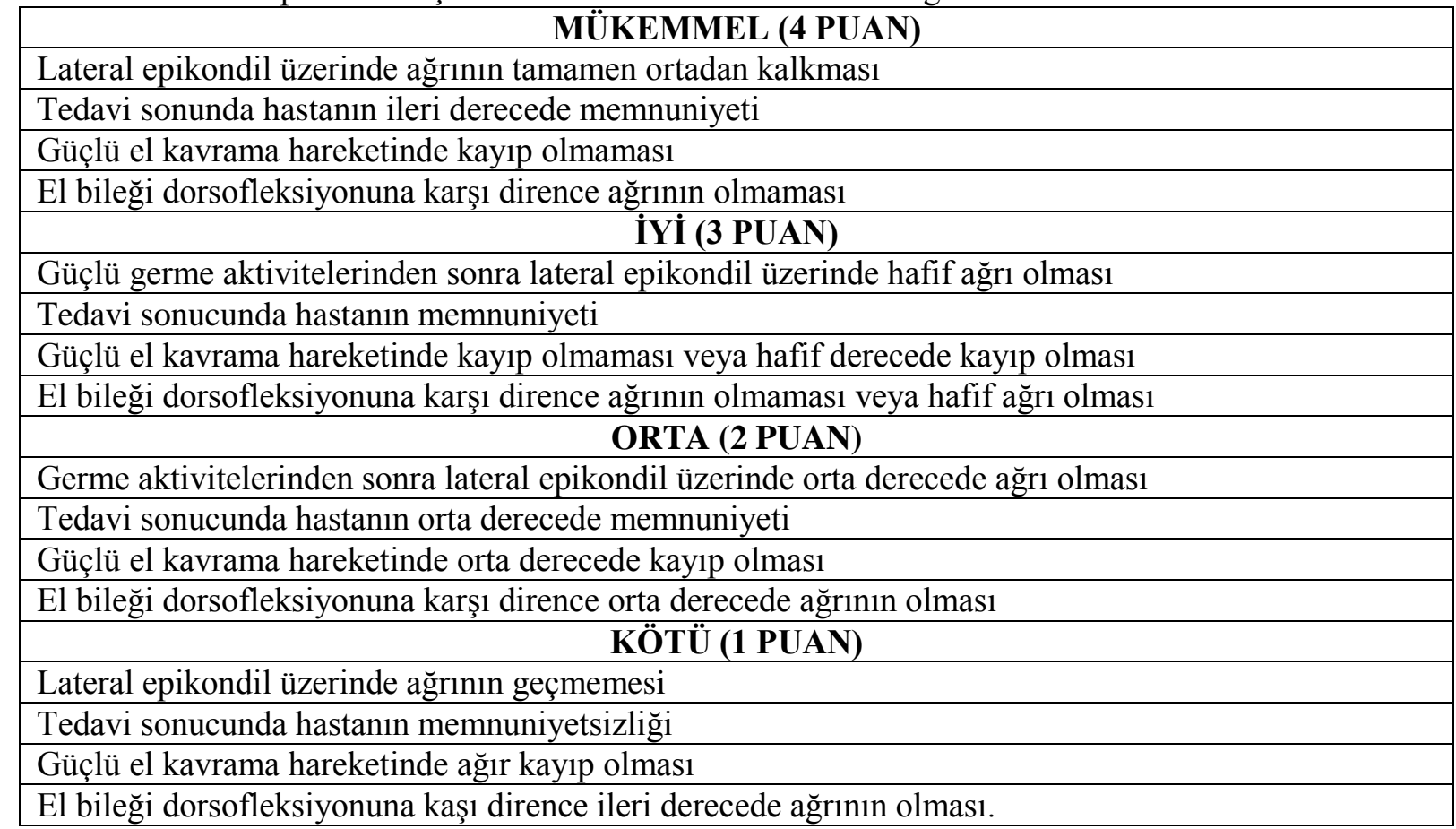

Tablo 2: Grup içi tedavi öncesi ve sonrası el kavrama güçleri ve iki grup arası el kavrama gücünde değişim fark1. 


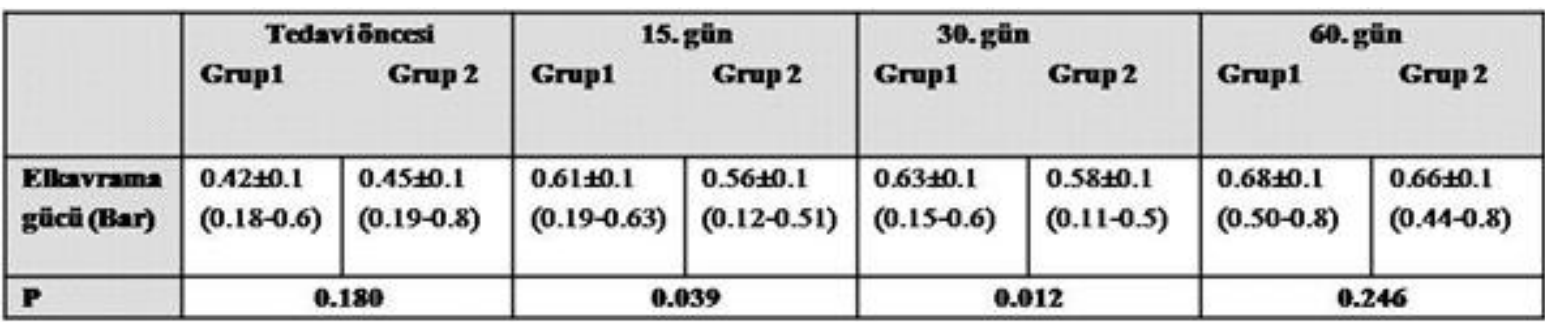

Tablo 3: Lokal steroid ve TZP uygulanan tedavi gruplarında 15-30 ve 60. günlerde Verhaar klinik fonksiyonel skorları.

\begin{tabular}{|c|c|c|c|c|c|c|}
\hline & \multicolumn{2}{|c|}{ Verhasar 15.gün } & \multicolumn{2}{|c|}{ Verhasar 30_gün } & \multicolumn{2}{|c|}{ Verhaar 60_gün } \\
\hline & Grup1 & Grup 2 & Grup1 & Grup 2 & Grup1 & Grup 2 \\
\hline Verhaarskoru & $\begin{array}{l}3.71 \pm 0.4 \\
(3-4)\end{array}$ & $\begin{array}{l}2.93 \pm 1 \\
(1-4)\end{array}$ & $\begin{array}{l}3.35 \pm 0.8 \\
(1-4)\end{array}$ & $\begin{array}{l}3.07 \pm 1.0 \\
3(1-4)\end{array}$ & $\begin{array}{l}3.61 \pm 0.6 \\
(1-4)\end{array}$ & $\begin{array}{l}3.55 \pm 0.7 \\
(1-4)\end{array}$ \\
\hline $\mathbf{P}$ & \multicolumn{2}{|c|}{0.002} & \multicolumn{2}{|c|}{0.028} & \multicolumn{2}{|c|}{0.720} \\
\hline
\end{tabular}
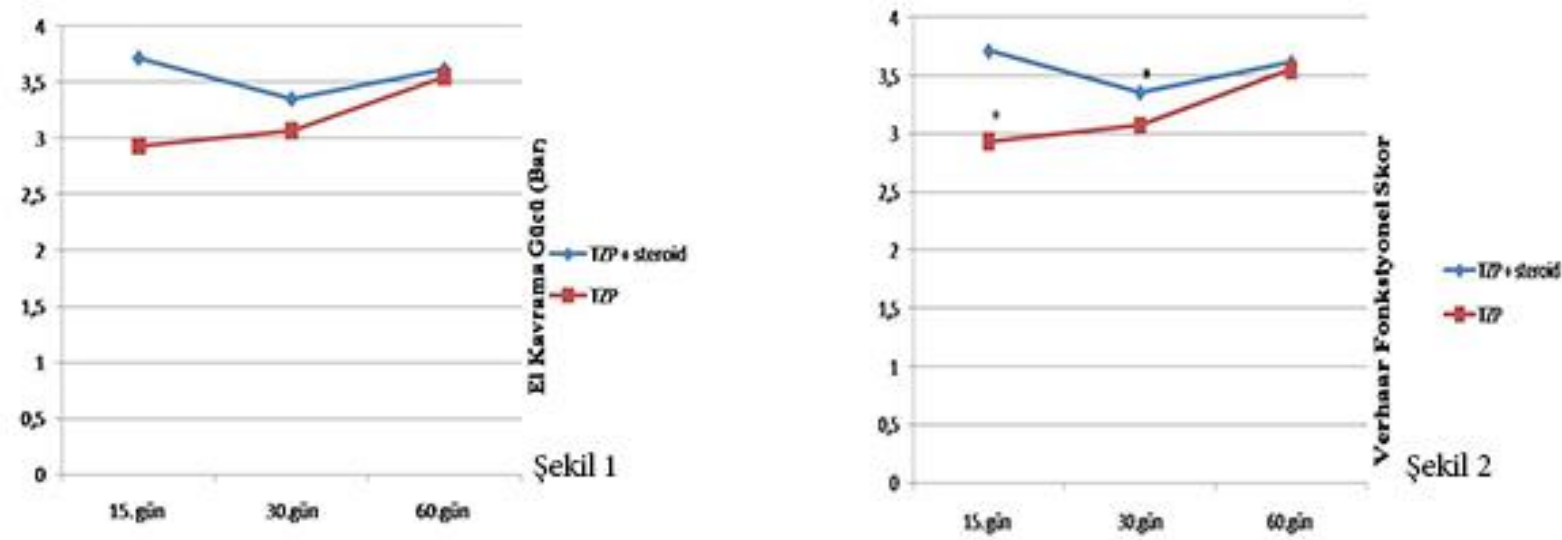

Şekil 1: Sadece TZP ile karşılaştırıldığında TZP + steroid enjeksiyon tedavisinin 15 ve 30 . gününde el kavrama gücünde belirgin artış, 2: Sadece TZP ile karşılaştıııldı̆̆ında TZP + steroid enjeksiyon tedavisinin 15 ve 30 . gününde klinik fonksiyonel sonuçlarda belirgin iyileşme

\section{Tartışma}

Bir çok çalışma, lateral epikondilitin tedavisi konusunda farklı tedavi yöntemleri (cerrahi, enjeksiyon tedavileri, medikal, egzersiz) ile farklı sonuçlar bildirmekle beraber primer tanı sonras1 tedaviye konservatif yöntemlerle başlanması gerektiği konusunda yaygın bir görüş hakimdir (9-12). En yaygın kullanılan 2 konservatif tedavi yöntemi olan epikondilit bandaj1 ve NSAİ ilaç tedavisinin özellikle dirençli olgularda el kavrama gücü ve fonksiyonel sonuçlar üzerindeki etkisi tartışmalıdır. Son dönemde bu alandaki eksiği kapatmak amaciyla farklı tedavi modaliteleri gündeme gelmiş; TZP, otolog tam kan ve steroid enjeksiyonu tedavisi ön plana çıkmakla beraber, literatürde bu zamana kadar TZP ve steroid kombinasyonu uygulanması ve klinik etkinliği değerlendirilmemiştir (13). Çalışmamızda, steroid ve TZP enjeksiyonu literatürde kombine olarak ilk kez kullanılmış ve tedavinin erken döneminde, el kavrama gücü ve hasta memnuniyeti açısından sadece TZP uygulamasına göre üstün olduğu tespit edilmiştir. Güncel literatürde, TZP tedavisi 
sonucunda hasta memnuniyetini inceleyen pek çok çalışma olmasına rağmen, bu çalışma, hasta memnuniyetinin yanı sira, TZP uygulamasının el kavrama gücü üzerinde etkisini araştıran ilk çalışma olma özelliğindedir (14).

Lateral epikondilitin fizyopatolojisi hala tartışma konusu olmakla beraber etiyolojik neden olarak humerus lateral epikondiline yapışan el bileği ekstensörlerinin aşırı kullanılması ve buna bağlı ekstensör karpi radialis brevisin muskulotendinoz kısmının yırtığ 1 ve tamir dokusunun abartılı inflamatuar reaksiyonu olduğu bildirilmiştir (15-17). Yapılan çalışmalarda ekstensör tendonların derin kısmında vaskülaritenin azalmış olduğu ve iyileşme dokusu için gerekli immün hücre, büyüme faktörü ve sitokin yetersizliğinden bahsedilmiştir (18).

Epikondilit bandaj1 tekrarlayan aktiviteler ile el bileği ektensörlerinin başlangıç noktasına yük binmesini azaltmak icin tasarlanmıştır. Bu bandajın hem vibrasyon amplitüdünü hem de ivmeyi azaltmada etkili olduğu düşünülmüş ancak tek başına yeterli olmadığı ispatlanmıștır $(19,20)$. NSAİ ilaç kullanımı ise ağrının başlangıcını ve lokalizasyonunu tam olarak ifade edemeyen, ağrısız intervaller tarif eden hasta grubunda tercih edilebilir. Verhaar skorlama sistemi ve el kavrama gücü değerlendirildiğinde steroid uygulamasına göre epikondil bantının ve NSAİ etkilerinin daha yavaş ve düşük olması, tek başına kullanımlarını sınırlandırabilir. Cerrahi tedavi seçeneği, şikayetlerin başlangıcından itibaren 1 y1l geçmesine rağmen konservatif tedavi yöntemlerine cevap vermeyen dirençli olgularda tercih edilmesi önerilmektedir. (21)

Çalışmamızda 2 konservatif tedavi yöntemine farklı etkinlik düzeylerinde ve zamanlarında dahi olsa, el kavrama gücü, ağrı ve hasta memnuniyeti açısından olumlu yanıt alınması, sadece seçilmiş olgularda cerrahi tedavi seçeneğinin düşünülmesi gerektiği görüşünü desteklemektedir. Tedaviye mümkün olan en erken dönemde başlanması önerilmekle beraber çalışmamızda şikayet süresi ve etkilenen taraf el kavrama gücü arasında anlamlı korelasyon bulunmadi. Konservatif tedavi ile literatürde \%60-90 oranında geniş bir spektrumda başarı bildirilmesi, tercih edilen yöntemler arasındaki farkların iyi bilinmesi ve hastaya göre seçim yapılması gerekliliğini ortaya koymaktadır.
Tek başına lokal steroid enjeksiyonu, uygulanabilirliği ve maliyet yarar dengesi göz önüne alındığında diğer konservatif yöntemler arasından öne çıkmaktadır. Literatürde lokal steroid enjeksiyonundan sonra ağrının akut azaldığı, fonksiyonel iyileşme sağladığı fakat uzun dönem takiplerinde semptomların tekrarlayabildiği belirtilmektedir. Gossel ve ark. yaptığı bir çalışmada sadece steroid uygulamasının TZP uygulamasına kıyasla ağrı ve fonksiyonel skorlarda iyileşme yönünden daha az kalıcı olduğu bildirilmiştir. Peerbooms ve ark. yaptığ 1 çalışmada ise yine TZP ile ortauzun dönemde daha iyi fonksiyonel sonuçlar bildirmişlerdir (22-24). Çalışmamızda elde ettiğimiz veriler, ağrı ve fonksiyonel sonuçlar açısından literatürdeki çalışmaları destekler niteliktedir ancak her iki tedavi modalitesinin el kavrama gücüne etkisi, kısa dönemde gruplar arası farklılık göstermektedir. Verhaar skoru ve el kavrama gücünün steroid enjeksiyonu + TZP uygulanan grup 1'de erken dönemde (15. ve 30. gün) anlamlı artış göstermesi, 60. günde ise 2 grup arasında fark olmamas1, erken dönemde iyi fonksiyonel sonuçlar elde etmek için steroid enjeksiyonunun TZP uygulaması ile kombine edilmesinin gerekliliğini göstermektedir. Etki mekanizmasının, erken dönmede görülen aşırı doku reaksiyonunun, steroidin antienflamatuar ve antiproliferatif etkisi ile baskılanmas1, orta dönemde ise hipovaskülariteye bağlı yetersiz büyüme faktörü ve sitokin açığının TZP'nin ihtiva ettiği büyüme faktörleri (PDGF, TFG- $\beta$ ve VEGF) ile kapatılmasına bağlı olduğunu düşünmekteyiz. Sandrey, kronik tendinopatilerde otolog büyüme faktörlerinin önemine işaret etmiştir (25). Benzer olarak, çalışmamızda elde edilen veriler, dirençli epikondilit olgularında kronikleşmenin engellenmesi açısından yetersiz olan büyüme faktörlerinin lokal olarak otojen büyüme faktörleri ile replase edilmesi gerekliliğini göstermiştir. Steroid + TZP uygulanan grupta 15 ve 30. gün ortalama el kavrama gücü değerlerinin ve Verhaar skorlarının daha yüksek bulunması, el kavrama gücünün daha kısa sürede geri dönme gerekliliği olan hasta populasyonunda (cerrah, sporcu, işci, şöför v.b) tercih sebebi olabilir.

Çalışmamız, kısa- orta dönem sonuçları vermekte olup, sadece steroid enjeksiyonu uygulanan hasta grubu bulunmaması bir dezavantaj teşkil etmektedir, ancak olguların 
dirençli lateral epikondilit olgusu olmaları nedeniyle sadece steroid enjeksiyonu ile tedavi protokolü uygulanamamıştır.

Sonuç olarak kronik epikondilit tedavisinde 1 hafta ara ile otolog TZP ve lokal tek doz steroid uygulamas1, erken dönemde anti-inflammatuar orta dönemde ise büyüme faktörlerinin etkisi ile etkin bir rejeneratif iyileşme sağlamaktadır. Çalışmada kullanılan kombine tedavi modalitesi, etkinliğin hızlı başlıyarak, 2. aya kadar progresif olarak artmasını sağlamıştır. Elde edilen veriler 1şı̆̆ında her 2 tedavi seçeneği arasında tercih, hastanın yaşı, mesleği, tedaviden beklentisi, teşhis ile tedavi arasında geçen süre kriterleri göz önüne alınarak yapılmalıdır. Özellikle genç, el kavrama gücünün hızlı ve kalıcı geri kazanılmas1 gereken meslek grubunda, otolog $\mathrm{TZP}+$ lokal steroid enjeksiyonu güvenli ve etkili bir yöntem iken, yaşlı, dejenere ve hypovasküler zeminde kronikleşme eğilimi olabilecek durumlarda ise tek başına TZP tedavisi akılcı bir tedavi yaklaşımı olacaktır.

\section{Çıkar çakışması: Yok}

\section{Kaynaklar}

1. Barrington $\mathrm{J}$, Hage W. Lateral epicondylitis (tenis elbow): nonoperative, open, or arthroscopic treatment?. Curr Opin Orthop 2003;14:291-5

2. Nirschl RP. Elbow tendinosis/tennis elbow. Clin Sports Med 1992;11:851-70

3. Chard MD. The Elbow. In Hochberg MC, Silman AJ, Smolen JS, Weinblatt ME, Weisman MH, editors. Rheumatology. 3rd ed. Mosby, London; 2003. p. 631-9

4. Coonrad RW, Hooper WR. Tennis elbow: its course, natural history, conservative and surgical management. J Bone Joint Surg Am 1973;55:1177-82

5. Keus SHJ, Smidt N, Assendelft WJJ. Treatment of lateral epicondylitis in general practice: result of a survey. Eur Gen Pract 2002;8:71-2

6. Peerbooms JC, Sluimer J, Bruijn DJ, Gosens T. Positive effect of an autologous trombosit concentrate in lateral epicondylitis in a double-blind randomized controlled trial: trombosit-rich plasma versus corticosteroid injection with a 1-year follow-up. Am J Sports Med 2010;38:255-62

7. Labelle H, Guibert R, Joncas J, Newman N, Fallaha $\mathrm{M}$, Rivard $\mathrm{CH}$. Lack of scientific evidence for the treatment of lateral epikondylitis of the elbow. An atempted meta-analysis. J Bone Joint Surg $\mathrm{Br}$ 1992;74:646-51

8. Verhaar JA, Walenkamp GH, van Mameren H, et al. Local corticosteroid injected versus Cyriax-type physiotherapy for tenis elbow. J Bone Joint Surg Br 1996;7:128-32

9. Akpınar S, Hersekli MA, Demirors H, Tandoğan RN. Lateral epikondilitte artroskopik gevsetme (olgu sunumu). Artroplasti Artroskopik Cerrahi 2001;12:87-90

10. Nirschl RP. Elbow tendinosis/tenis elbow. Clin Sport Med 1992;11:851-70

11. Kraushaar BS, Nirschl RP. Tendinosis of the elbow (tenis elbow):Clinical features and findings of histological immunohistochemical and electron microscopy studies. J Bone Joint Surg 1999;81:25979

12. Schneeberger AG, Masquelet AC. Arterial vascularization of the proximal axtensor carpi radialis brevis tendon. Clin Orthop 2002;398;239-44

13. Smidt N, van der Windt DA, Assendelf WJ, et al. Corticosteroid injections, physiotherapy, or a widtand-see policy for lateral epicondylitis: a randomized controlled trial. Lancet 2002;359:657-62

14. Altay T, Gunal I, Ozturk H. Local injection treatment for lateral epicondylitis. Clin Orthop 2002;398:12730

15. Belhan O, Karakurt L. Humerus lateral epikondilit tedavisinde lokal steroid enjeksiyonu ile lateral epikondilit bandajının etkinliğinin karşılaştırılması. Firat Tip Dergisi 2008;13:24-7

16. Walther M, Kirschner S, Koenig A, et al. Biomechanical evaluation of braces used for treatment of epicondylitis. J Shoulder Elbow Surg 2002;11:265-70

17. Boyer MI, Hastings II H. Lateral tenis elbow: "Is there any science out there?". J Shoulder Elbow Surg 1991;8:481-91

18. Solveborn SA, Buch F, Mallmin H, et al. Cortisone injection with anesthetic additives for radial epicondylalgia (tennis elbow). Clin Orthop 1995;316:99-105

19. Verhaar JAN, Walenkamp GHIM, van Mameren H, Kester ADM, van der Lindan AJ. Lokal corticosteroid injection versus cyriaxtype physiotherapy for tenis elbow. J Bone Joint Surg 1996;78B:128-32 